\title{
TRABAJOS DE LA LECTURA, LECTURAS DE LA VIOLENCIA. LO CREATIVO - LO DESTRUCTIVO EN EL PENSAMIENTO DE WINNICOTT Ricardo Rodulfo
}

\author{
Adriana Anfusso \\ Licenciada en Psicología de la UDELAR \\ Profesora adjunta del IUPA \\ Miembro Habilitante de la AUDEPP \\ Miembro del Board Latinoamericano de los Encuentros Winnicott \\ Correo electrónico: adriana.anfusso@gmail.com
}




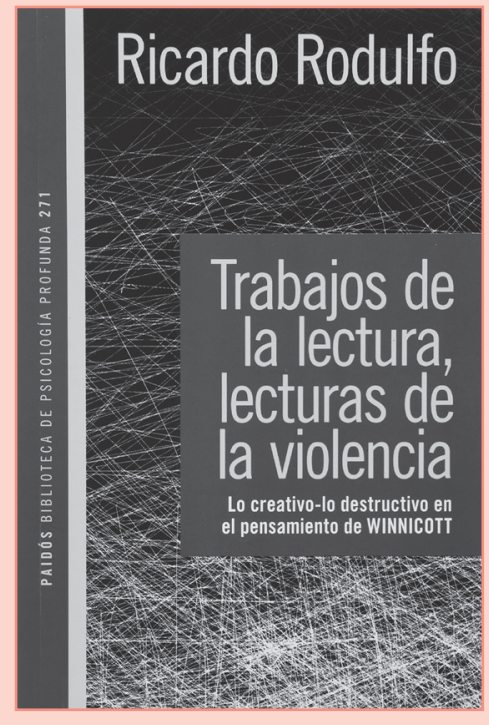

Título: Trabajos de la lectura, lecturas de la violencia. Lo creativo - lo destructivo en el pensamiento de Winnicott Autor: Ricardo Rodulfo Año: 2009

Editorial: Paidós

Ciudad: Buenos Aires

Páginas: 266 


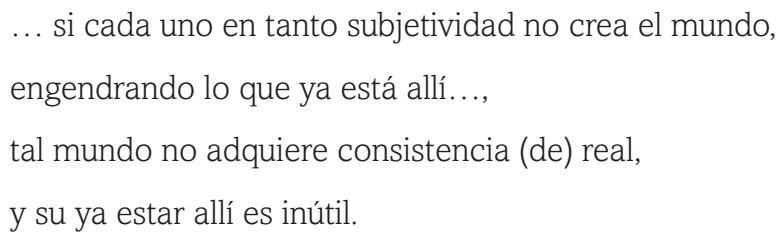

Ricardo Rodulfo (2009, p.41).

Ricardo Rodulfo es psicólogo y psicoanalista especializado en niños y adolescentes, doctor en Psicología y catedrático en la Universidad de Buenos Aires, y director de la Fundación Estudios Clínicos en Psicoanálisis. Se trata de una figura muy conocida y respetada en nuestro medio, especialmente en la AUDEPP, donde sus visitas suelen provocar asombros, adhesiones y un torbellino de ricos intercambios y cuestionamientos.

Ha publicado más de quince libros, muchos solo y otros en colaboración con colegas, además de innumerables artículos en revistas y periódicos. Prolífico conferencista, en la actualidad ofrece online Seminarios de Formación en Psicoanálisis de Niños y Adolescentes, con la colaboración de su esposa, Marisa Punta.

Rodulfo se concentra lúcidamente en los temas más complejos, discutibles y discutidos, también los menos frecuentados, de la obra de Donald Woods Winnicott. Por esta razón, quizás no sea este el libro más indicado para principiantes, aunque sin duda alguna resultará tremendamente esclarecedor y desafiante para quienes, habiendo ya incursionado en los textos de Winnicott, deseen profundizar y reavivar el interés por su obra.

Los diecisiete capítulos que componen este libro son de muy variada naturaleza y pueden leerse independientemente, ya que cada uno posee unidad conceptual. Algunos presentan casuística clínica del autor. 
Con ellos, Rodulfo va tejiendo en red los conceptos de Winnicott sobre origen, derivados, funciones y efectos, tanto positivos como negativos, de la agresividad y sus múltiples variantes.

En el índice se pueden encontrar algunos capítulos sobre temas conocidos: «Del self», «El falso self y su verdad», «Transición», «La capacidad para estar solo», «El jugar sin fundamento»y otros cuantos con títulos abstractos y algo enigmáticos que despiertan curiosidad: «Nada», «Raíz», «Inercia», «La integración sin síntesis», «Oposición y ambigüedad», «Violencia de necesidad», entre otros.

Rodulfo explica el formato de su libro asemejándolo a la práctica de la escritura musical. Dice: «Tanto su estilo no académico como la naturaleza de las cuestiones a tratar me llevaron en este libro, sin proponérmelo, a elegir el procedimiento musical de la "variación", del motivo de la variación y de la variación del motivo» (p.21).

Sin verbos a la vista, la peculiar sintaxis del título opera como un primer llamador, que el diseño gráfico de la tapa refuerza. Con letra grande y destacada, se lee: «Trabajos de la lectura, lecturas de la violencia», frase nominal que se refiere a los dispositivos metodológicos que el autor utilizó para escribir este libro. Recién más abajo, y con letra mucho más pequeña, puede leerse el concepto que hilvana las ideas allí expuestas: «Lo creativo - lo destructivo en el pensamiento de Winnicott». Rodulfo parece subrayar que el camino recorrido importa más que el objetivo a alcanzar.

Las singularidades del título remiten a la experiencia personal de Rodulfo. Él confiesa que no fueron las lecturas rápidas, sino otras muy cuidadosas, por propia cuenta y sin intermediarios, las que le permitieron captar la profundidad de sentido y la importancia del vuelco ideológico que Winnicott introduce en este particular campo del psicoanálisis que está analizando. Fue tal modalidad lo que le permitió hacerse de un nuevo Winnicott, por lo que ahora comparte y recomienda el método a sus eventuales lectores para que, a su vez, cada uno construya el suyo 
propio. Nada podría alegrar más a Winnicott, un abanderado del self, de la mismidad.

Rodulfo dedica especial atención a las especulaciones de Winnicott en torno a lo constructivo y sus contrapartidas habituales, más particularmente a la propuesta de una fuerza vital originaria única, de carácter constructivo-destructivo con la «cualidad de lo viviente», de un amor primitivo que contiene «agresión, motilidad, espontaneidad, vivacidad, fuerza vital» (p.165). Recuerda que «Winnicott constantemente se pregunta por una raíz propia de la agresión o de la violencia» sin remitirlas a «alguna pulsión y menos aún a una pulsión de muerte» (p.143). Y agrega el dato de que «Winnicott y Lacan coinciden en obviar toda posible referencia a una pulsión de muerte como fuente originaria de la agresión» (p. 144).

Los guiones que unen y separan y lo transicional, elementos tan propios de Winnicott, constituyen para Rodulfo un asunto que merece atención. A ellos se refiere como bordes o membranas «donde ocurren los procesos verdaderamente importantes» (p.119). Son como fronteras inestables o puertas batientes hechas para ir y venir, que mezclan sin hacer desaparecer del todo las diferencias y presentan ante nuestros ojos continentes poco explorados, como los del amor-odio, la madre-bebé o lo interno-externo. Se trata de unidades duales paradójicas que desplazan a la unidad tradicional e incluso al concepto de sujeto. Para discurrir sobre estas nuevas unidades de tipo yo-otro o dos-en-uno, Rodulfo acude a pensadores que le son afines, como Jacques Derrida, Zeljko Loparic y Jessica Benjamin.

Rodulfo desbarata los argumentos que presentan a Winnicott como un autor fácil y ameno cuyo único aporte habría sido el de lo transicional, mero complemento de las teorías reconocidamente fundacionales. Por el contrario, con entusiasmo contagioso cuenta cómo, al sumergirse en su obra, llegó a una «experiencia de descubrimiento» que le permite definir 
a Winnicott como «un pensador dentro y con el psicoanálisis» (p.14), un pensador «de la existencia humana» (p.19).

Es interesante un detalle que Rodulfo coloca en primer plano: la frecuencia con que, muy desenvuelto y en varios de sus escritos, Winnicott se refiere a «mi teoría del desarrollo» (p.15). Interpreta el hecho como señal inequívoca de que Winnicott tenía conciencia plena de la originalidad y la libertad de su pensamiento.

También, Rodulfo comenta cómo debió esforzarse por develar para sí mismo (y de paso se lo devela a sus lectores) el sentido que Winnicott quiso dar a muchos conceptos que emplea de forma por demás idiosincrática. Así lo exige su frecuente uso de neologismos y las variaciones o ampliaciones de significado que aplica a términos ya extensamente consensuados. Se afana por transmitir de forma muy directa su personal visión del desarrollo humano y del tratamiento.

Entre 1955 y 1959, Winnicott escribió mucho sobre la agresividad. A una de sus formas se refirió como «agresión creativa», gesto que, si logra como respuesta la supervivencia y la no retaliación del ambiente, creará la externalidad, la alteridad y lo transicional. La «agresión destructiva» o «agresión reactiva», en cambio, es la que surge cuando expresiones tempranas de la fuerza vital, de la violencia inherente a todo bebé humano, que surge de la «motilidad, la espontaneidad o la vivacidad, reciben un choque temprano [...] por parte de un medio hostil» (p.166). En su opinión, estas intrusiones cierran el paso a los grados necesarios de oposición que necesita el bebé para poder crecer y desarrollarse, y suelen ser antecedentes de patología.

Winnicott se pregunta una y otra vez cuál es la raíz propia de la agresión. Rodulfo sostiene que hacerlo equivale a no aceptar que su origen es la frustración y a aceptar aun menos que lo sea la pulsión de muerte. Y lo resume, sin duda y con firmeza, así: «Punto clave que otra vez separa 
a Winnicott del resto: Winnicott no asimila agresión = pulsión de muerte $=$ destructividad $=$ originariedad primitiva, como, entre otros, lo hace Klein» (p.139).

Winnicott propone un giro copernicano al plantear la hipótesis de una fuerza vital inicial constructivo-destructiva, el amor-discordia o amorlucha. En los capítulos 8, 9, 10 y 11 es donde esos temas y otros colaterales están más desarrollados. $\mathrm{Al}$ abordar asuntos disruptivos como este, Rodulfo suele homologar a Winnicott con Derrida porque ambos comparten el «denuedo por desmarcarse de la tradición del "logos” y sus unidades conceptuales» y el «rechazo a la adaptación como criterio rector de valor terapéutico y el modo rotundo en que la asimilan a sumisión pura y simple, no cuando hay adaptación, cuando "solo" hay adaptación» (p.249).

La lectura de estas lecturas de Rodulfo sobre lo constructivo-destructivo en Winnicott genera una rica experiencia en la que convergen la sorpresa y el asombro, el interés y la curiosidad, al igual que la duda y los deseos de saber, todo lo cual nos hace sentir más vivos. 
